\title{
Analisis Anisotropi Suseptibilitas Magnetik Batuan Beku Lengan Utara Sulawesi
}

\author{
Melisa Rongkonusaa*, Gerald Tamuntuana, Guntur Pasaua \\ aJurusan Fisika, FMIPA, Unsrat, Manado
}

KATA K U N C I

Batuan beku, Kemagnetan

batuan, Anisotropi

suseptibilitas magnetik

\begin{abstract}
A B S T R A K
Telah dilakukan penelitian untuk menentukan pola anisotropi suseptibilitas magnetik dan status singkapan batuan beku dari pola yang diperoleh. Pengukuran anisotropi suseptibilitas magnetic dilakukan pada lima sampel batuan beku dari Sulawesi Utara menggunakan Bartington MS2B. Arah pengukuran sampel disesuaikan dengan desain Tauxe.

Hasilnya menunjukkan bahwa suseptibilitas maksimum terdistribusi disekitar arah utara dan timur. Sedangkan suseptibilitas intermediet dan minimum terdistribusi disekitar Utara-Timur dan Timur-Selatan. Elipsoida suseptibilitas cenderung prolate atau lebih lonjong. Batuan beku yang dianalisis merupakan kelompok batuan terobosan yang mekanisme lelehannya terjadi secara vertikal.
\end{abstract}

K E Y W O R D S

Igneous rock,

Rock magnetism,

Anisotropy of magnetic susceptibility

\begin{abstract}
A B S T R A C T
$A$ research has been conducted to determine the anisotropic pattern of magnetic susceptibility and the status of igneous rocks exposure from the obtained pattern. We have measured the anisotropy of magnetic susceptibility on five samples of igneous rock from North Sulawesi by Bartington MS2B. The position of samples were adjusted according to the Tauxe's design.

The result shows that the maximum susceptibility is distributed around northward and eastward, while the intermediate and minimum susceptibility are distributed around nortward-eastward and eastwardsouthward. The susceptibility ellipsoid tends to be prolate or more oval. This shows that the igneous rocks that have been analyzed are group of intrusive rocks which melting mechanism occurs through vertical fracture.
\end{abstract}

TERSEDIA ONLINE

1 Februari 2017

\section{Pendahuluan \\ Pulau Sulawesi memiliki letak geografis yang unik karena berada pada pertemuan tiga lempeng tektonik besar yaitu lempeng Eurasia, lempeng Indo- Australia, dan lempeng Indo-Pasifik. Otofuji dkk (1981) dan Surmont dkk (1994) telah melakukan kajian tentang geodinamika dan evolusi tektonik Pulau Sulawesi, secara khusus pada lengan utaranya, namun mendapatkan hasil yang menggambarkan arah pergerakan lempeng relatif berbeda.}

Batuan beku merupakan salah satu objek yang sangat potensial untuk kajian evolusi tektonik (Ngkoimani dkk, 2005; Tauxe, 2008). Informasi rekaman magnetik pada batuan beku dapat diperoleh melalui analisis sifat-sifat magnetik yang diantaranya adalah anisotropi suseptibilitas magnetik.

Karakteristik sifat-sifat magnetik batuan beku yang berada pada lengan utara Pulau Sulawesi hingga saat ini belum diketahui secara mendalam. Oleh karena itu, pada penelitian ini telah dilakukan karakterisasi sifat-sifat mineral magnetik dari daerah tersebut dengan menggunakan metode kemagnetan batuan (rock magnetism). Penelitian ini bertujuan untuk menentukan pola anisotropi suseptibilitas magnetik batuan beku dan menentukan status singkapannya dari pola yang diperoleh. Hasil penelitian ini dapat dijadikan

*Corresponding author: Jurusan Fisika FMIPA UNSRAT, Jl. Kampus Unsrat, Manado, Indonesia 95115; Email address: melisa_rongkonusa@yahoo.com Published by FMIPA UNSRAT (2017) 
sebagai data awal untuk rekonstruksi evolusi tektonik Pulau Sulawesi.

\section{Material dan Metode}

\subsection{Batuan Beku}

Igneous Rocks atau batuan beku adalah batuan yang terbentuk sebagai akibat dari pembekuan magma. Berdasarkan tempat terjadinya, batuan beku terbagi menjadi dua jenis, yaitu batuan beku intrusif (Intrusive rocks) dan batuan beku ekstrusif (Ekstrusive rocks).

\subsection{Kemagnetan Batuan}

Ditinjau dari sifat magnetiknya, mineral dikelompokkan menjadi diamagnetik, paramagnetik dan feromagnetik.

Sifat dari suatu mineral magnetik dipengaruhi oleh bentuk dan ukuran dari bulir-bulir (grains) mineral tersebut. Ukuran bulir berkaitan dengan domain magnetik. Bulir magnetik yang kecil akan cenderung untuk memiliki satu domain dan karenanya disebut bulir berdomain tunggal atau single domain (SD). Sebaliknya, bulir yang lebih besar akan mempunyai domain yang banyak dan karenanya disebut bulir berdomain jamak atau multi domain (MD).

\subsection{Suseptibilitas Magnetik Batuan}

Jika intensitas medan magnet luar $H$ diberikan pada suatu bahan, maka bahan tersebut akan memberikan respon yang disebut dengan magnetisasi $M$. Hubungan kedua besaran tersebut dinyatakan dalam persamaan :

$$
M=\chi H
$$

dimana $M$ adalah momen magnetik per satuan volume $(\mathrm{A} / \mathrm{m}), H$ adalah intensitas medan magnetik,

$\chi$ adalah faktor pembanding yang dikenal dengan suseptibilitas magnetik.

Magnetisasi yang dimiliki oleh bahan karena disebabkan medan magnet luar yang mempengaruhinya disebut magnetisasi induksi. Besarnya induksi magnetik di dalam material dapat dinyatakan sebagai berikut

$$
B=\mu_{0}(H+M)=\mu_{0}(1+\chi) H=\mu H
$$

\subsection{Anisotropy of Magnetic Susceptibility (AMS)}

Suatu sampel batuan dikatakan anisotropi secara magnetik jika sifat-sifat magnetiknya bergantung pada arah pengukuran. Sebaliknya, jika sifat - sifat magnetiknya sama pada semua arah pengukuran, maka sampel batuan tersebut dikatakan isotropi secara magnetik (Bijaksana, 2004).

Dalam pengukuran, yang terbaca adalah bukan besarnya magnetisasi tetapi besarnya vektor polarisasi magnetik imbas $J$, dimana $J=\mu_{0} H$ dan $\chi$ merupakan tensor simetri orde dua. Tensor yang demikian dapat dinyatakan secara lengkap dengan elipsoida triaksial dengan suseptibilitas utama $X_{1}, X_{2}$, $x_{3}\left(X_{1}>x_{2}>x_{3}\right)$.

\subsection{Metode Penelitian}

Sampel yang digunakan pada penelitian ini adalah batuan beku yang diambil di beberapa lokasi di wilayah Sulawesi Utara, yaitu Minahasa, Tomohon, Minahasa Utara dan Bitung. Penelitian dilaksanakan pada bulan Mei 2015 sampai Juli 2016.

Proses pengukuran anisotropi suseptibilitas magnetik menggunakan 5 (lima) sampel batuan beku pada masing-masing situs di beberapa lokasi penelitian, yaitu Batu Putih (Bitung), Treman (Minahasa Utara), Tondano (Minahasa) dan Kinilow (Tomohon). Sampel dipreparasi di Jurusan Fisika Universitas Sam Ratulangi Manado kemudian pengukuran dilanjutkan di Laboratorium Paleomagnetik ITB dengan alat Bartington Magnetic Susceptibility Meter model MS2. Posisi sampel terorientasi pada enam arah pengukuran menurut desain Tauxe (2014).

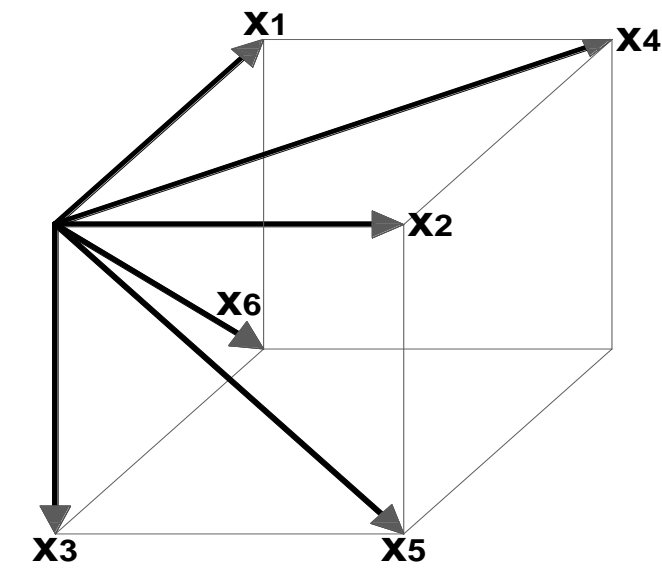

Gambar 2.1. Arah Pengukuran (Tauxe,2014)

Berdasarkan arah-arah pengukuran sebagaimana ditunjukkan pada Gambar (2.1), cosinus arah dari pada setiap pengukuran adalah sebagai berikut.

$\begin{array}{lll}\mathrm{A}_{1}(1, & 0, & 0) \\ \mathrm{A}_{2}(0, & 1, & 0) \\ \mathrm{A}_{3}(0, & 0, & 1) \\ \mathrm{A}_{4}(1 / \sqrt{2}, & 1 / \sqrt{2}, & 0) \\ \mathrm{A}_{5}(0, & 1 / \sqrt{2}, & 1 / \sqrt{2}) \\ \mathrm{A}_{6}(1 / \sqrt{2}, & 0, & 1 / \sqrt{2})\end{array}$

sehingga suseptibilitas pada 6 arah pengukuran dapat dituliskan sebagai berikut:

$$
\begin{aligned}
& A_{1}=\chi_{11} \\
& A_{2}=\chi_{22} \\
& A_{3}=\chi_{33} \\
& A_{4}=1 / 2 \chi_{11}+1 / 2 \chi_{22}+\chi_{12} \\
& A_{5}=1 / 2 \chi_{22}+1 / 2 \chi_{33}+\chi_{23} \\
& A_{6}=1 / 2 \chi_{11}+1 / 2 \chi_{33}+\chi_{31}
\end{aligned}
$$

Matriks untuk pola pengukuran berordo $6 \times 6$ menjadi: 


$$
A=\left[\begin{array}{cccccc}
1 & 0 & 0 & 0 & 0 & 0 \\
0 & 1 & 0 & 0 & 0 & 0 \\
0 & 0 & 1 & 0 & 0 & 0 \\
0,5 & 0,5 & 0 & 1 & 0 & 0 \\
0 & 0,5 & 0,5 & 0 & 1 & 0 \\
0,5 & 0 & 0,5 & 0 & 0 & 1
\end{array}\right]
$$

digambarkan dalam bentuk plot stereonet (Tarling dan Hrouda

\section{Hasil dan Pembahasan}

Pemecahan matriks dilakukan dengan menggunakan program khusus dalam bahasa Matlab untuk menentukan nilai eigen. Dengan mengacu pada nilai suseptibilitas magnetik terukur, maka nilai suseptibilitas magnetik untuk masingmasing site ditampilkan dalam Tabel 3.1.

Dalam penelitian ini digunakan beberapa faktor anisotropi yang bertujuan melihat sejauh mana anisotropi suseptibilitas magnetik data penelitian yang diambil. Faktor-faktor tersebut menurut Jelinek (1981) adalah derajat anisotropi (P $\left.=\chi_{1} / \chi_{3}\right)$, lineasi magnetik $\left(\mathrm{L}=\chi_{1} / \chi_{2}\right)$, foliasi magnetik $\left(F=\chi_{2} / \chi_{3}\right)$ dan faktor bentuk $(\mathrm{T}=(\ln \mathrm{F}$ $-\ln \mathrm{L}) /(\ln \mathrm{F}+\ln \mathrm{L}))$.

Tabel 3.1 Nilai Suseptibilitas Magnetik

\begin{tabular}{|l|l|l|l|l|}
\hline \multirow{2}{*}{ No } & \multirow{2}{*}{ Kode Sampel } & \multicolumn{3}{|c|}{ Suseptibilitas Magnetik $\left(\times 10^{-3}\right)$} \\
\cline { 3 - 5 } & & \multicolumn{1}{|c|}{$X_{1}$} & \multicolumn{1}{|c|}{$X_{2}$} & $X_{3}$ \\
\hline 1 & BP1 & 1287,8 & 1173,7 & 1112,8 \\
\hline 2. & BP2 & 1445,3 & 1259,9 & 1144,9 \\
\hline 3. & IRM & 843,8 & 711,3 & 654,1 \\
\hline 4. & IDNO & 668,4 & 568,0 & 550,7 \\
\hline 5 & KINI & 730,8 & 619,3 & 647,6 \\
\hline
\end{tabular}

Berdasarkan analisis parameter AMS, secara umum batuan yang dianalisis termagnetisasi relatif anisotropik dengan persen derajat $\geq 10 \%$ sebagaimana ditunjukkan oleh Gambar 3.1.

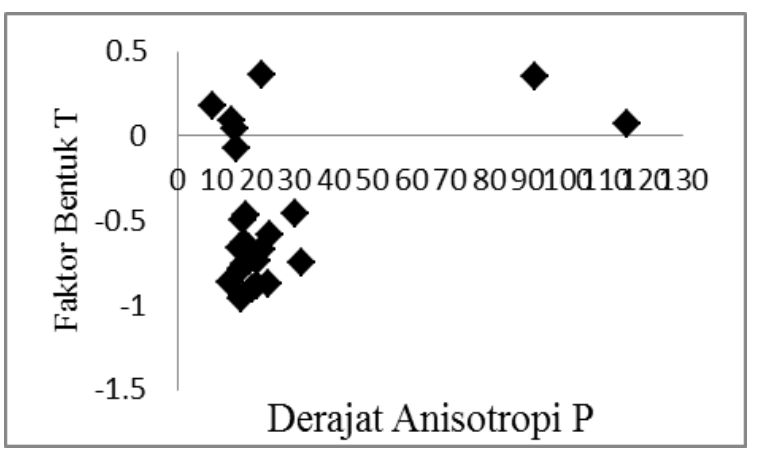

Gambar 3.1. Plot derajat anistropi (P) tehadap faktor bentuk ( $\mathrm{T}$ ) untuk semua sampel pada semua situs.

Faktor bentuk dapat merepresentasikan bentuk elipsoida suseptibilitas dimana $-1 \leq T \leq 1$. Bentuk elipsoida suseptibilitas yang dicirikan oleh kelonjongan atau kepipihan dapat ditunjukkan oleh plot hubungan antara foliasi (F) terhadap lineasi (L) atau yang dikenal dengan Flinn-type plot. Sedangkan untuk memudahkan interpretasi terhadap elipsoida suseptibilitas, maka suseptibilitas maksimum, menengah, dan minimum digambarkan dalam bentuk plot stereonet (Tarling dan Hrouda, 1993). Masing-masing nilai suseptibilitas diberi kode kotak (suseptibilitas maksimum), segitiga (suseptibilitas menengah) dan bulat (suseptibilitas minimum).

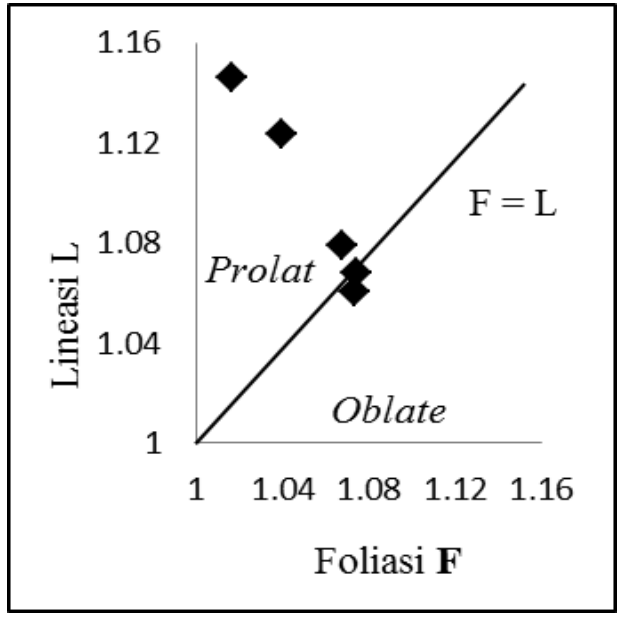

Gambar 3.2. Flinn-type Plot Situs BP1

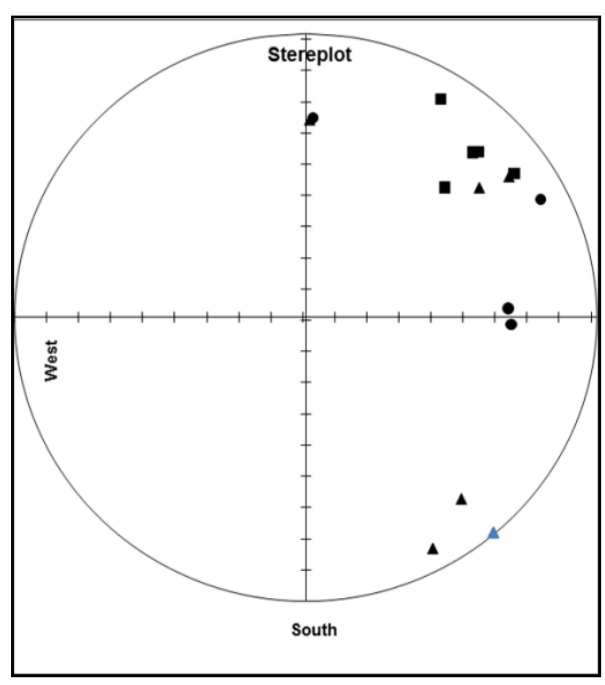

Gambar 3.3. Stereoplot Situs BP1

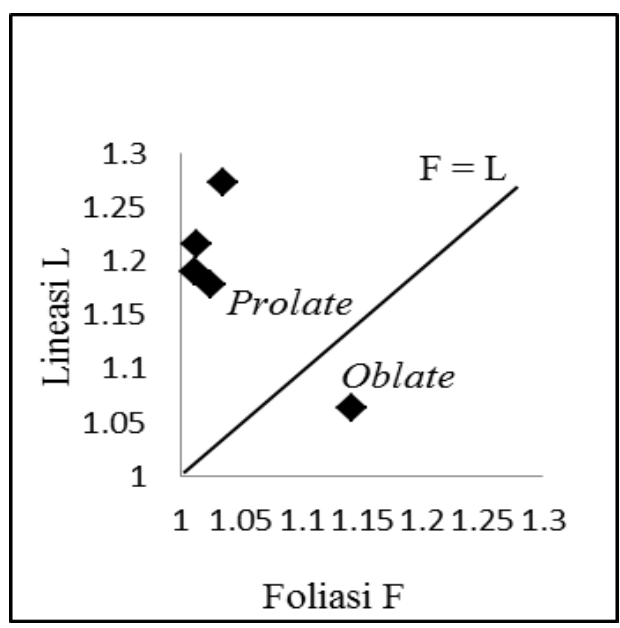

Gambar 3.4. Flinn-type Plot Situs KINI 


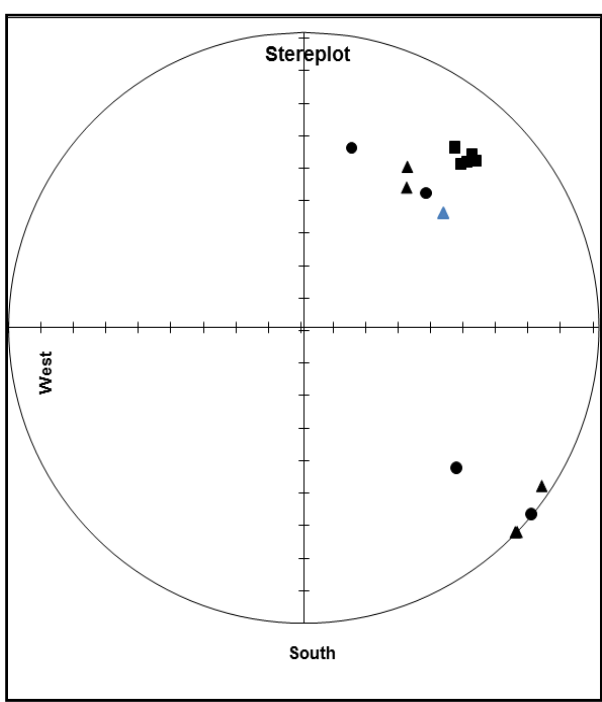

Gambar 3.5. Stereoplot Situs KINI

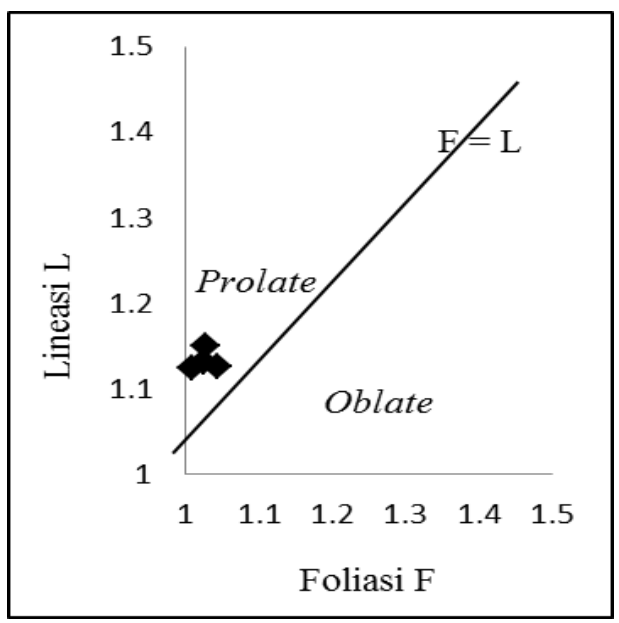

Gambar 3.6. Flinn-type Plot Situs TRM

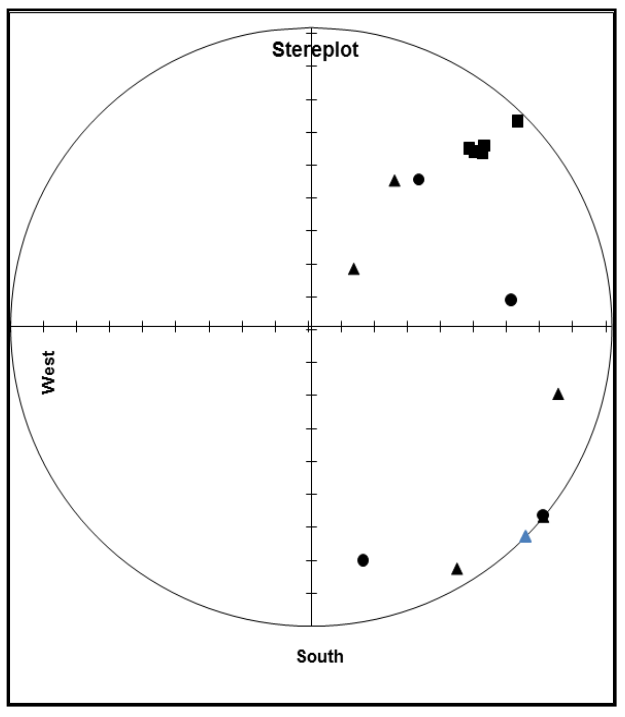

Gambar 3.7. Stereoplot Situs TRM

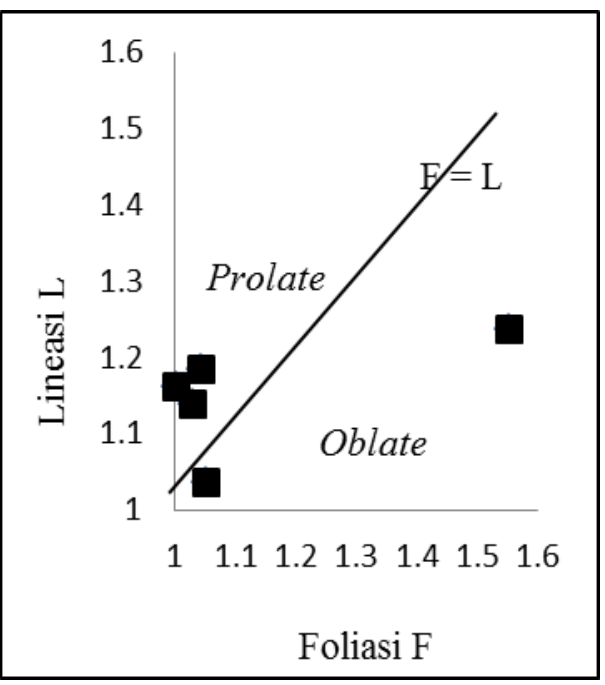

Gambar 3.8. Flinn-type Plot Situs BP2

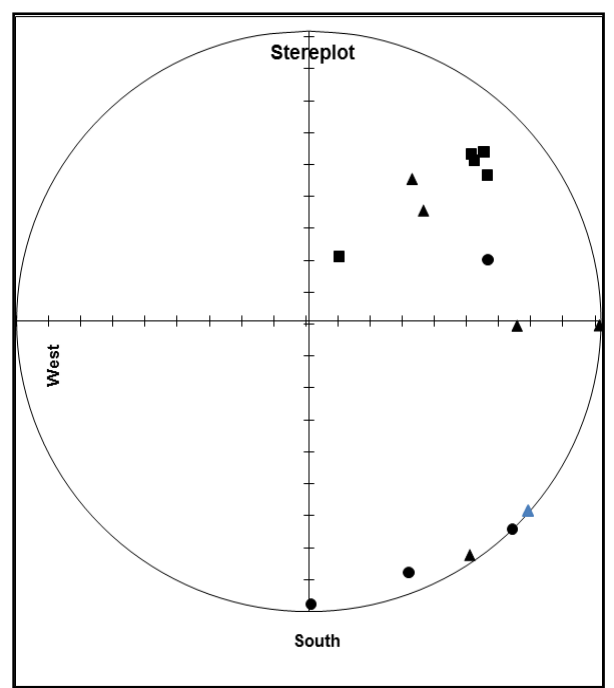

Gambar 3.9. Stereoplot Situs BP2

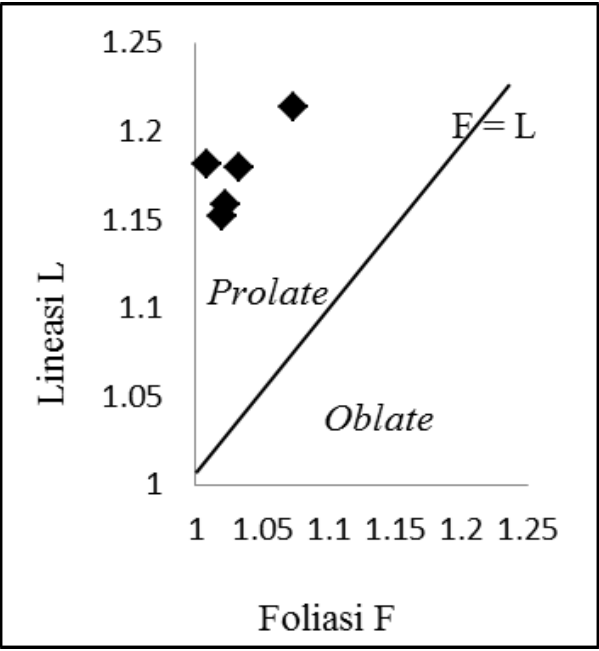

Gambar 3.10. Flinn-type Plot Situs TDNO 


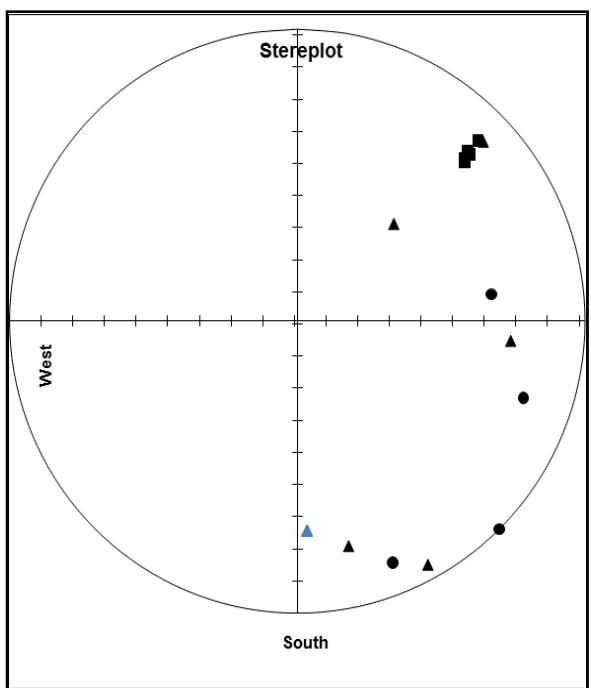

Gambar 3.11. Stereoplot Situs TDNO

Berdasarkan variasi nilai faktor bentuk anisotropi suseptibilitas magnetik ( $T$ ) sebagian besar sampel berada pada rentang $-1<\mathrm{T}<0$. Menurut Bijaksana (1991), jika nilai T berada pada rentang $-1<\mathrm{T}<0$ maka merepresentasikan bahwa nilai lineasi magnetik lebih dominan. Sehingga nilai ini mengindikasikan bahwa sampel yang dianalisis lebih didominasi oleh lineasi. Dominasi lineasi ini merepresentasikan bentuk elipsoida suseptibilitas yang cenderung prolate atau lonjong.

Pola AMS batuan beku menunjukkan sumbu suseptibilitas maksimum terdistribusi antara arah Utara dan Timur, sedangkan suseptibilitas intermediet dan minimum terdistribusi antara arah Utara-Timur dan Timur-Selatan. Hasil ini memberikan gambaran bahwa batuan beku yang dianalisis merupakan kelompok batuan terobosan (intrusi, dyke, atau sill). Jika batuan tersebut merupakan kelompok batuan lelehan, maka mekanisme lelehannya terjadi melalui rekahan yang berarah vertikal.

3. Kesimpulan

1) Pola AMS batuan beku menunjukkan sumbu suseptibilitas maksimum terdistribusi antara arah Utara dan Timur, sedangkan suseptibilitas intermediet dan minimum terdistribusi antara arah Utara-Timur dan Timur-Selatan.

2) Batuan beku yang dianalisis merupakan kelompok batuan intrusi yang mekanisme lelehannya terjadi melalui rekahan secara vertikal.

\section{Daftar Pustaka}

Bijaksana, S. 1991, Magnetic Anisotropy of CretaceousDeepSea Sedimentary Rocks From the Pasific Plate. [Thesis]. Memorial University of Newfoundland, $44-55$

Bijaksana, S. 2002. Karakterisasi Magnetik. Himpunan Fisika Indonesia. Jurnal Fisika HFI. 5(0527).
Bijaksana, Satria, 2004. Ulasan Tentang Landasan Fisis Anisotropi Magnetik Pada Batuan. Jurnal Geofisika, Volume 1.

Graha, 1987. Batuan Dan Mineral. Nova. Bandung. Ngkoimani, L., Bijaksana, S., Mahrizal, Abdulah, C.I., Liong, T.H., 2005. Magnetic Properties of Igneous Rocks from Banyuwangi, East Java, and Their Reliability for Paleomagnetic Study. Indonesian Journal of Physics. 16(2): 33-41.

Paul A.Tipler, (2001). Fisika untuk Sains dan Teknik, Jilid 1, Penerbit Erlangga.

Tarling DH, Hrouda F (1993). The magnetic anisotropy of rocks. Chapman \& Hall, London 217.

Tauxe, L, Banerjee, S.K., Butler, R.F. and van der Voo $\mathrm{R}, 2014$. Essentials of Paleomagnetism, 3rd Web Edition. 